\title{
ASSOCIATION BETWEEN ADMINISTRATION OF ANTACID MEDICATION AND ANASTOMOTIC STRICTURE FORMATION FOLLOWING REPAIR OF OESOPHAGEAL ATRESIA
}

Ceri E Jones, ${ }^{1}$ Rachel Smyth, ${ }^{1}$ Melanie Drewett, ${ }^{1}$ David M Burge, ${ }^{1}$ Nigel J Hall ${ }^{1,2}$

1. Department of Paediatric Surgery and Urology, Southampton Children's Hospital, Southampton, UK

2. University Surgery Unit, University of Southampton, Southampton, UK

Author contributions:

Study concept: $\mathrm{NH}, \mathrm{MD}, \mathrm{DB}$

Study design: $\mathrm{NH}, \mathrm{DB}, \mathrm{CJ}$

Data collection: CJ, MD, RS

Data analysis: $\mathrm{CJ}, \mathrm{RS}, \mathrm{NH}$

Report writing: CJ, RS

Report review: $\mathrm{MD}, \mathrm{DB}, \mathrm{NH}$

Correspondence address:

Mr Nigel Hall

Associate Professor

University Surgery Unit

Mailpoint 816

University of Southampton

Tremona Road

Southampton

SO16 6YD

Tel: 02381206146

E-mail: n.j.hall@soton.ac.uk 


\section{Abstract}

Aims of study: Anastomotic stricture is a significant cause of morbidity following repair of oesophageal atresia (OA). Exposure to gastric acid has been postulated to contribute to stricture development and severity leading to prophylactic antacid use by some surgeons. We investigated the association between administration of antacid medication and the development of anastomotic strictures.

Methods: Retrospective case-note review of consecutive infants undergoing repair of OA with distal tracheoesophageal fistula (Type C) between Jan 1994 and Dec 2014. Only infants who underwent primary oesophageal anastomosis at initial surgical procedure were included. Stricture related outcomes were compared initially for infants who received prophylactic antacid medication versus no prophylaxis, and the role of prophylactic antacid medication in stricture prevention was explored in a multivariate model. Outcomes were also compared for infants grouped by antacid use at any stage.

Results: One hundred fourteen infants were included. Sixteen received prophylactic antacid medication at surgeon preference. Of the remaining 98,44 subsequently received antacid as treatment for gastro-oesophageal reflux (GOR) and 54 never received antacid medication. There was no statistically significant association between incidence of stricture in the first year (10/16 vs 41/98; $p=0.18$ ) nor time to first stricture (median 57 days [41-268] vs 102 days [43-320]; $p=0.89$ ) and administration of prophylactic antacid medication. Similarly there were no statistically significant associations between incidence of stricture, age at first stricture and number of dilatations, and administration of antacid medication either as prophylaxis nor when given as treatment for symptoms or signs of GOR.

Conclusions: These data do not support the hypothesis that prophylactic antacid medication reduces the incidence or severity of anastomotic stricture following repair of OA. Treatment with antacids may be best reserved for those with symptoms or signs of GOR. Further prospective investigation of the role of antacid prophylaxis on stricture formation following OA repair is warranted.

Keywords: oesophageal atresia; anastomotic stricture; oesophageal dilatation; gastrooesophageal reflux; antacid medication 


\section{Introduction}

Oesophageal atresia is a rare congenital anomaly affecting between 1 in 2500-5000 live births worldwide, with 150-200 cases per year in the UK. ${ }^{1}$ Survival rates from surgical repair have increased even in infants considered to be at high risk of mortality such as those with significant congenital cardiac disease and low birth weight. ${ }^{2}$ The quality of survival is now an even more important factor in the long-term management of these children.

Anastomotic strictures following repair of oesophageal atresia are reported to occur in up to $50 \%$ of patients, contributing to significant morbidity that can result in respiratory complications, periods of poor nutrition and impact upon quality of life. ${ }^{3}$ Management of these strictures involves repeated dilatations under general anaesthetic, multiple hospital admissions and further oesophageal surgery for recalcitrant strictures.

Gastro-oesophageal reflux (GOR) is a common finding in infants following oesophageal atresia repair and many infants are managed with antacid medications. It has been postulated that antacid medications may reduce the incidence of anastomotic stricture and some international organisations currently recommend that infants should be prophylactically prescribed antacid medication in the first year following oesophageal atresia repair to reduce the risk of anastomotic stricture formation. ${ }^{4}$ However, the current published literature has little evidence to support these recommendations ${ }^{5}$ and some study findings suggest a higher incidence of stricture when prophylactic antacid medication (PAAM) is used. ${ }^{1,6}$ Furthermore routine use of antacid medication without evidence of specific benefit is not without the potential for harm. ${ }^{7,8}$ Therefore it is important to consider the relative benefits and risks of PAAM medication in this population.

The aim of this study is to investigate the association between PAAM and development of anastomotic stricture in infants with type $C$ oesophageal atresia.

\section{Methods}

We performed a retrospective case-note review of consecutive infants who underwent surgical repair of oesophageal atresia between January 1994 and December 2014 at our centre. Cases were identified via a prospectively maintained database of neonatal surgical admissions over this time period. For the purposes of this study and to exclude heterogeneity that may be related to subtype of oesophageal atresia, we included only cases of Type $C$ oesophageal atresia (with distal TOF) that underwent primary oesophageal anastomosis at the initial surgical procedure. Other anatomical arrangements of oesophageal atresia /TOF and cases that did not achieve oesophageal continuity at the initial surgical procedure (e.g. cases of TOF ligation followed by delayed primary anastomosis) were excluded. Only cases for which there was a minimum of one year confirmed follow-up were included.

Demographic and clinical data were recorded including gestational age, birth weight, sex, tension at anastomosis (as judged by operating surgeon), pre-operative ventilation (as a marker of urgency of case), use of antacid medication post-operatively and episodes of 
anastomotic dilatations. Outcome data were recorded on a bespoke data collection sheet for this study up to most recent clinical follow-up.

Cases were divided into groups for comparison based on the use of antacid medication. This was deemed prophylactic (PAAM group) if specified to be started post-operatively by the operating surgeon and started within 48hours of the primary surgery. All other infants were deemed not to have received PAAM.

The primary outcome was the incidence of anastomotic stricture at less than one year of age with a stricture defined as need for anastomotic dilatation. During the study period, elective calibrations/dilatations were not performed nor were routine post-operative contrast studies. Secondary outcomes were anastomotic stricture at any time in follow up, age at first dilatation, number of dilatations within first year of life and beyond, further surgery and use of antacid medications at any time. Duration of follow-up was also recorded.

During the analysis we identified that some infants who did not receive PAAM were commenced subsequently on antacid medication during follow-up either as evidence of gastro-oesophageal reflux became apparent or as part of treatment of an anastomotic stricture. The group who did not receive PAAM were therefore divided further into two groups; those who receive antacid medication during follow-up (treatment group) and those who did not. Outcomes were compared between these groups.

Data are median (interquartile range) or number (\%) of cases. The Shapiro-Wilk normality test was applied to continuous data. Data for variables that satisfied the criteria for normality were compared using students t-test and data that did not satisfy criteria for normality were compared using Mann Whitney and Kruskal Wallis tests. Between group comparisons for dichotomous data were done using Fisher's exact test. The relationship between demographic and clinical factors and anastomotic stricture was explored using multivariate logistic regression analysis to allow us to take into account factors other than just antacid medication use which may influence stricture formation. These were defined $a$ priori and were birth weight, gender, pre-operative ventilation, tension at anastomosis, and use of a trans-anastomotic tube. Statistical analysis was performed using SPSS v22 (IBM). This study was part of a retrospective review approved by the UK National Research Ethics Service (15/WA/0153).

\section{$\underline{\text { Results }}$}

During the study period 168 newborn infants with oesophageal atresia +/- TOF were treated at our institution. Of these, 122 cases met the inclusion criteria for this study as being oesophageal atresia with distal TOF undergoing primary oesophageal anastomosis at the initial surgical procedure. One case was excluded as there was incomplete data for analysis and seven cases were excluded because their care was transferred to another centre before one year of age (including five in the neonatal period), thereby precluding assessment of the primary outcome. The remaining 114 cases were included. For these 114 cases, median gestational age was 39 weeks (37-40) and birth weight 2.8kg (2.4-3.1). Median duration of follow up was $4.9 y$ rs (3.1y-8.57yrs). All infants survived the neonatal period. 
Sixteen infants received PAAM (all ranitidine) versus 98 who did not. Infant demographics and clinical features were similar between these groups (Table 1). At the primary operation $5 / 16(31 \%)$ of the PAAM group and $15 / 98(15 \%)$ of the No prophylaxis group were described as having tension at the anastomosis. By 1 year of age, 10/16 (63\%) of the PAAM group versus $41 / 98$ (41\%) in the No prophylaxis group had developed a stricture. Of those infants undergoing at least one dilatation the median number of dilatations in the first year of life was 3 (1-5). Overall there was no difference in number of dilatations between groups (Table 1).

Of 98 patients not receiving prophylactic antacid medication, 44 (45\%) were treated with antacid medications for symptoms or signs of GOR or as treatment of stricture during the follow up period (Figure 1). Stricture related outcomes were compared between these groups and found to be similar (Table 2). Further surgery for recalcitrant stricture was performed in one case in each of these three groups (strictureplasty $n=1$, cervical oesophagostomy $n=1$, gastric transposition $n=1$ ). Six children subsequently had a fundoplication performed; 0/16 in the PAAM group, 4/44 in the GOR treatment group and $2 / 54$ in the no antacid group.

In multivariate analysis adjusting for other factors that may influence development of anastomotic stricture, the use of PAAM was not significantly associated with the development of a stricture within the first year of life (Table 3 ), nor the number of dilatations needed within the first year of life $(p=0.84)$. We noted however that both male sex and anastomotic tension were significantly associated with stricture in this multivariate analysis.

\section{Discussion:}

Following repair of oesophageal atresia, many surgeons routinely use PAAM with the intention of reducing oesophageal acid exposure. ${ }^{9-11}$ Drawing parallels with the recognised causative link between gastro-oesophageal acid reflux and oesophageal stricture, the belief is that PAAM will reduce the incidence and perhaps the severity of anastomotic stricture following oesophageal atresia repair. Despite this practise being relatively widespread and having been adopted into a number of sets of international guidelines, ${ }^{4}$ there is no strong evidence to support its use. ${ }^{5}$ Due to a known variation in practice between surgeons in our centre we analysed our data. Overall, our findings are similar to those reported in a small number of similar studies ${ }^{1,6,12-14}$ and a more recent meta-analysis ${ }^{5}$ in that there was no significant association between PAAM and the incidence of anastomotic stricture, nor the number of dilatations needed.

It is interesting that both we and some others previously found that the incidence of stricture was actually higher (albeit non-statistically significantly) in infants treated with PAAM than those without. ${ }^{16}$ This is clearly contrary to the rationale for which PAAM are being used. One possible explanation is that PAAM are preferentially used in infants in whom there is a 'tight' oesophageal anastomosis and that it is the tension on the anastomosis that contributes to stricture formation. Our multivariate analysis suggests that a 'tight' oesophageal anastomosis is indeed significantly associated with anastomotic 
stricture. Whilst the use of PAAM was higher in cases with anastomotic tension $(5 / 20,25 \%)$ than those without $(11 / 94,12 \%)$, our adjusted analysis suggests that despite this, PAAM was not associated with a reduction in the incidence or severity of stricture. Due to the nature of this study we are unable to delineate further the contributory factors to stricture formation. As a sensitivity analysis we evaluated the incidence of stricture in relation to PAAM use in the 100 infants not judged to have a 'tight' anastomosis. In concurrence to our main results, incidence of stricture in the first year of life was similar in infants who received PAAM 45\% (5/11 infants) compared to those who did not receive PAAM (37\% [31/83]; $p=0.74)$.

Of infants who did not receive PAAM, just under half were subsequently treated with antacid medication for GOR or as treatment of a stricture. The incidence of stricture was higher (61\%) in those who were started on antacid medication during follow up than those who were not (46\%) but this did not reach statistical significance. These data therefore provide no evidence of benefit of antacid medication on incidence or severity of stricture in these groups. . We acknowledge that there are other indications for commencing antacid medication in infants with oesophageal atresia other than stricture prevention. An analysis of the effectiveness of this is beyond the scope of this study.

Given the ease of availability and relative low cost of antacid medication some may ask why not just give PAAM to all infants following surgical repair of oesophageal atresia. Certainly some guidelines propose this ${ }^{4}$ and we are aware that it is a relatively widespread practice. ${ }^{9-}$ ${ }^{11}$ However we challenge this approach for a number of reasons. Firstly, no parent wishes to give their child medication unless there is a definite benefit (and currently evidence of benefit does not exist). Secondly, although PAAM is a relatively cheap intervention, there clearly are cost implications of starting an infant on medication. Other uncertainties include: how long should PAAM be continued and when should it be stopped? Perhaps most importantly however is the fact that there may be some disadvantages to routine use of PAAM when there is no proven benefit. Stomach acid is known to act as an antimicrobial barrier and reducing the efficacy of this has been shown to be clinically important in infants. For example a number of studies have reported a positive association between the use of ranitidine and both sepsis and death in neonates. ${ }^{7,8,15} \mathrm{In}$ older otherwise healthy children (4-36 months) an association has been reported between used of medication that reduces gastric acidity and gastroenteritis and community acquired pneumonia. ${ }^{16}$ Other reported associations with the use of antacid medications in infants include increased risk of Clostridium difficile infection, ${ }^{17}$ allergy ${ }^{18}$ and obesity ${ }^{19}$ in childhood.

The limitations of this study are that is was performed as a retrospective review over a 20 year period with the inherent biases of such a study. However we are confident we have included all patients since cases were identified from a prospectively maintained departmental database. We cannot assure compliance with PAAM with those who were commenced on it beyond the initial hospital stay. Our definition of a stricture was based upon need for dilatation. Symptoms leading to dilatation may have differed between cases since the decision for dilatation was at surgeon discretion rather than being protocol driven. However we did not perform 'routine' oesophageal dilatation during this time period meaning that all dilatations were performed for symptomatic strictures. The description of a tight anastomosis is subjective and may be prone to inter-operator variation. We 
acknowledge that the number of patients in the PAAM group is a relatively small proportion of the cohort. Consequently our study is underpowered to detect a difference in stricture rate between groups but the direction of the association between PAAM and anastomotic stricture is not even in a direction consistent with this hypothesis. Our further analysis with the use of the antacid medication at any time goes someway to addressing this sample size limitation and still the direction of the association is not consistent with the underlying hypothesis. Of note the overall stricture rates are comparable with other published literature.

\section{Conclusions:}

These data do not support the hypothesis that prophylactic antacid medication reduces incidence or severity of anastomotic strictures following repair of oesophageal atresia. Treatment with antacid medications may be best reserved for those with symptoms or signs of GOR. Other data suggest there may be risks associated with the use of antacid medication, hence the benefit of treatment is uncertain when a strong treatment indication is lacking. Further rigorous prospective clinical investigation should be undertaken to determine if routine PAAM confers any benefit following oesophageal atresia repair. If found to be ineffective then the use of PAAM may be avoided, reducing risk of adverse associations in these infants. If, however, PAAM is truly effective at reducing incidence of anastomotic stricture then surgeons could prescribe these with confidence of their benefit and importantly their use could be justified in all infants following oesophageal atresia repair.

\section{Declarations of interest: none}

Funding: this research did not receive any specific grant from funding agencies in the public, commercial, or not-for-profit sectors 
Table 1: Clinical features and stricture related outcomes in infants receiving prophylactic antacid medication and those not

\begin{tabular}{|c|c|c|c|}
\hline & $\begin{array}{l}\text { Prophylactic } \\
\text { antacid } \\
(n=16)\end{array}$ & $\begin{array}{l}\text { No prophylaxis } \\
(n=98)\end{array}$ & $p+$ \\
\hline \multicolumn{4}{|l|}{ Clinical features } \\
\hline BW (kg) & $2.9(2.8--3.2)$ & $2.8(2.3-3.1)$ & 0.08 \\
\hline GA (wks) & $39(38-40)$ & $39(36-40)$ & 0.60 \\
\hline Sex $M: F$ & $11: 5$ & $66: 32$ & 1.0 \\
\hline Pre-op ventilation & $1(6 \%)$ & $15(15 \%)$ & 0.46 \\
\hline \multicolumn{4}{|l|}{ Operative factors } \\
\hline Tight anastomotic repair & $5(31 \%)$ & $15(15 \%)$ & 0.15 \\
\hline TAT used & $16(100 \%)$ & $90(92 \%)$ & 0.60 \\
\hline \multicolumn{4}{|l|}{ Outcomes } \\
\hline$\overline{\text { Stricture at }}<1 \mathrm{yr}$ of age & $10(63 \%)$ & $41(41 \%)$ & 0.18 \\
\hline $\begin{array}{l}\text { Number of dilatations in first } \\
\text { year }\end{array}$ & $1(0-4)$ & $0(0-2)$ & 0.22 \\
\hline Age at first stricture (days) $\ddagger$ & $57(41-268)$ & $102(43-320)$ & 0.89 \\
\hline Stricture at any time & $11(63 \%)$ & $52(53 \%)$ & 0.29 \\
\hline $\begin{array}{l}\text { Number of dilatations during } \\
\text { follow-up }\end{array}$ & $2(0-4)$ & $1(0-3)$ & 0.38 \\
\hline Duration of follow-up (yrs) & $3.6(2.5-9.1)$ & $5.2(3.1-18.3)$ & 0.06 \\
\hline \multicolumn{4}{|c|}{ Data are median (IQR) or number (\%) } \\
\hline $\begin{array}{l}\text { †Mann-Whitney, T-test or Fish } \\
\text { ‡Only for those who had a stri } \\
\text { TAT - Trans-anastomotic tube }\end{array}$ & $\begin{array}{l}\text { 's exact test as } \\
\text { ure }\end{array}$ & propriate & \\
\hline
\end{tabular}


Table 2: PAAM v GOR treatment v No antacids

\begin{tabular}{lcccc}
\hline & $\begin{array}{c}\text { Prophylactic } \\
\text { antacid } \\
(n=16)\end{array}$ & $\begin{array}{c}\text { Antacid as } \\
\text { treatment of } \\
\text { GOR }(n=44)\end{array}$ & $\begin{array}{c}\text { No antacids } \\
(n=54)\end{array}$ & $p^{+}$ \\
\hline $\begin{array}{l}\text { Stricture at }<1 \mathrm{yr} \\
\text { of age }\end{array}$ & $10(63 \%)$ & $19(43 \%)$ & $22(41 \%)$ & 0.30 \\
$\begin{array}{l}\text { Age at first } \\
\text { stricture (days) } \ddagger\end{array}$ & $57(41-268)$ & $111(44-377)$ & $92(40-266)$ & 0.66 \\
$\begin{array}{l}\text { Stricture at any } \\
\text { time in follow-up }\end{array}$ & $11(69 \%)$ & $27(61 \%)$ & $25(46 \%)$ & 0.17 \\
\hline
\end{tabular}

Data are median (IQR) or number (\%)

†Kruskal Wallis or Fishers exact test as appropriate

‡Only for those who had a stricture

Table 3: Multivariate logistic regression analysis of factors associated with development of stricture in first year of life

\begin{tabular}{lcccc}
\hline & \multicolumn{2}{c}{ Stricture in the first year of life } & & \multirow{2}{*}{$\mathrm{p}$} \\
\cline { 2 - 3 } & No $(\mathrm{n}=63)$ & Yes $(\mathrm{n}=51)$ & OR $(95 \% \mathrm{Cl})$ & \\
\hline Sex (Male) & $36(57 \%)$ & $41(80 \%)$ & $2.8(1.1-6.9)$ & 0.02 \\
Anastomotic tension & $5(8 \%)$ & $15(29 \%)$ & $4.2(1.3-13.5)$ & 0.02 \\
Pre-operative ventilation & $9(15 \%)$ & $7(14 \%)$ & $1.44(0.4-5.0)$ & 0.57 \\
PAAM used & $6(10 \%)$ & $10(20 \%)$ & $1.8(0.5-5.9)$ & 0.35 \\
TAT used & $57(90 \%)$ & $49(96 \%)$ & $2.5(0.4-14.1)$ & 0.31 \\
\hline
\end{tabular}

Model also adjusted for birthweight $(p=1.0)$

PAAM - prophylactic antacid medication; TAT- trans-anastomotic tube 
Figure 1: Flowchart of cases in this study

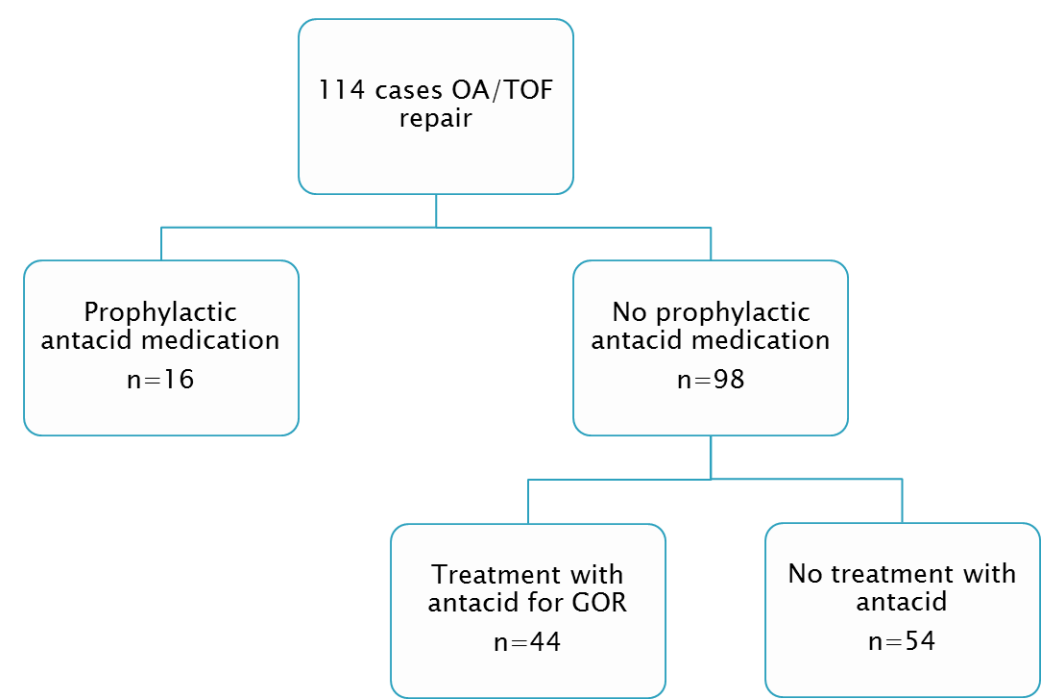

OA/TOF - oesophageal atresia with distal tracheo-oesophageal fistula; GOR - gastrooesophageal reflux 


\section{$\underline{\text { References }}$}

1. Allin B, Knight $M$, Johnson $P$, Burge $D$, Baps $C$. Outcomes at one-year post anastomosis from a national cohort of infants with oesophageal atresia. PLoS One 2014;9:e106149. https://doi.org/10.1371/journal.pone.0106149

2. Malakounides G, Lyon P, Cross K, Pierro A, De Coppi P, Drake D, et al. Esophageal Atresia: Improved Outcome in High-Risk Groups Revisited. Eur J Pediatr Surg 2016;26:22731. https://doi.org/10.1055/s-0035-1551567

3. Svoboda E, Fruithof J, Widenmann-Grolig A, Slater G, Armand F, Warner B, et al. A patient led, international study of long term outcomes of esophageal atresia: EAT 1. J Pediatr Surg 2018;53:610-5. https://doi.org/10.1016/i.jpedsurg.2017.05.033

4. Krishnan U, Mousa H, Dall'Oglio L, Homaira N, Rosen R, Faure C, et al. ESPGHANNASPGHAN Guidelines for the Evaluation and Treatment of Gastrointestinal and Nutritional Complications in Children With Esophageal Atresia-Tracheoesophageal Fistula. J Pediatr Gastroenterol Nutr 2016;63:550-70. https://doi.org/10.1097/MPG.0000000000001401 5. Miyake $H$, Chen $Y$, Hock A, Seo S, Koike Y, Pierro A. Are prophylactic anti-reflux medications effective after esophageal atresia repair? Systematic review and meta-analysis. Pediatr Surg Int 2018;34:491-7. https://doi.org/10.1007/s00383-018-4242-4

6. Hagander L, Muszynska C, Arnbjornsson E, Sandgren K. Prophylactic treatment with proton pump inhibitors in children operated on for oesophageal atresia. Eur J Pediatr Surg 2012;22:139-42. https://doi.org/10.1055/s-0032-1308698

7. Santana RNS, Santos VS, Ribeiro-Junior RF, Freire MS, Menezes MAS, Cipolotti R, et al. Use of ranitidine is associated with infections in newborns hospitalized in a neonatal intensive care unit: a cohort study. BMC Infect Dis 2017;17:375.

https://doi.org/10.1186/s12879-017-2482-x

8. Bianconi S, Gudavalli M, Sutija VG, Lopez AL, Barillas-Arias L, Ron N. Ranitidine and late-onset sepsis in the neonatal intensive care unit. J Perinat Med 2007;35:147-50. https://doi.org/10.1515/JPM.2007.017

9. Shawyer AC, Pemberton J, Flageole H. Post-operative management of esophageal atresia-tracheoesophageal fistula and gastroesophageal reflux: a Canadian Association of Pediatric Surgeons annual meeting survey. J Pediatr Surg 2014;49:716-9.

https://doi.org/10.1016/i.jpedsurg.2014.02.052

10. Burge DM, Shah K, Spark P, Shenker N, Pierce M, Kurinczuk JJ, et al. Contemporary management and outcomes for infants born with oesophageal atresia. Br J Surg 2013;100:515-21. https://doi.org/10.1002/bjs.9019

11. Lal DR, Gadepalli SK, Downard CD, Ostlie DJ, Minneci PC, Swedler RM, et al. Perioperative management and outcomes of esophageal atresia and tracheoesophageal fistula. J Pediatr Surg 2017;52:1245-51. https://doi.org/10.1016/i.jpedsurg.2016.11.046 12. Donoso F, Lilja HE. Risk Factors for Anastomotic Strictures after Esophageal Atresia Repair: Prophylactic Proton Pump Inhibitors Do Not Reduce the Incidence of Strictures. Eur J Pediatr Surg 2017;27:50-5. https://doi.org/10.1055/s-0036-1593607

13. Stenstrom P, Anderberg M, Borjesson A, Arnbjornsson E. Prolonged Use of Proton Pump Inhibitors as Stricture Prophylaxis in Infants with Reconstructed Esophageal Atresia. Eur J Pediatr Surg 2017;27:192-5. https://doi.org/10.1055/s-0036-1584179

14. Murase N, Uchida H, Kaneko K, Ono Y, Makita S, Yokota K. Prophylactic effect of H2 blocker for anastomotic stricture after esophageal atresia repair. Pediatr Int 2015;57:461-4. https://doi.org/10.1111/ped.12529 
15. Terrin G, Passariello A, De Curtis M, Manguso F, Salvia G, Lega L, et al. Ranitidine is associated with infections, necrotizing enterocolitis, and fatal outcome in newborns.

Pediatrics 2012;129:e40-5. https://doi.org/10.1542/peds.2011-0796

16. Canani RB, Cirillo P, Roggero P, Romano C, Malamisura B, Terrin G, et al. Therapy with gastric acidity inhibitors increases the risk of acute gastroenteritis and communityacquired pneumonia in children. Pediatrics 2006;117:e817-20.

https://doi.org/10.1542/peds.2005-1655

17. Brown KE, Knoderer CA, Nichols KR, Crumby AS. Acid-Suppressing Agents and Risk for Clostridium difficile Infection in Pediatric Patients. Clin Pediatr (Phila) 2015;54:1102-6. https://doi.org/10.1177/0009922815569201

18. Mitre E, Susi A, Kropp LE, Schwartz DJ, Gorman GH, Nylund CM. Association Between Use of Acid-Suppressive Medications and Antibiotics During Infancy and Allergic Diseases in Early Childhood. JAMA Pediatr 2018;172:e180315.

https://doi.org/10.1001/jamapediatrics.2018.0315

19. Stark CM, Susi A, Emerick J, Nylund CM. Antibiotic and acid-suppression medications during early childhood are associated with obesity. Gut 2019;68:62-9.

https://doi.org/10.1136/gutjnl-2017-314971 